\title{
Respiratory System Findings Reason For Exclusion From Statistics
}

National Cancer Institute

\section{Source}

National Cancer Institute. Respiratory System Findings Reason For Exclusion From

Statistics. NCl Thesaurus. Code C123991.

A rationale for excluding a particular data point or subject from the respiratory system statistical analysis. 